\title{
THE DOCTOR-MANAGER RELATIONSHIP
}

\begin{abstract}
Healthcare service in itself is one of the most crucial, most sensitive services in the world. Advancement in healthcare infrastructures, equipment and manpower are rapid day by day. "Healthcare service providers", the definition is changing from commonly perceived "doctors" to "doctors plus managers". The healthcare practice has changed all its way from individual practice to communal, organised hospital systems; resources are pooled in a common place; where patients expect for every kind of treatment once they enter the common roof. However, the hospital only can understand the role the doctor and manager play together for quality healthcare services. The two now cannot be separated despite of several disparities that appear between them. There should always be an effort to bridge the gap between them which appears between them despite serving the common goal. Doctor manager collaboration including collaboration of education system shall bring the real bond between them to understand each other, understand system and pace for their common goal.
\end{abstract}

For correspondence

CA. Raju Basnet Chhetri, Member (ICAI, ICAN), B.Com.(H)

Finance Controller,

Universal College of Medical Sciences,

Bhairahawa, Nepal

e-mail: raju.basnet.chhetri@gmail.com

financecontroller.ucms@gmail.com 


\section{INTRODUCTION:}

It is widely recognised that good relationships between doctors and managers are essential for efficient delivery of healthcare. Investigation of serious service failures often reveals inadequate teamwork, lack of clinical leadership or poor doctor-manager relationships. This article explores the relationship between two components of our healthcare system: physicians, representing all providers of direct care, and hospital executives, referring to those with administrative responsibilities, regulatory obligations, and resource control.

Currently, there is a wide gap, representing an adversarial interaction. Over the past 50 years, there have been dramatic, revolutionary, changes in the practice of medicine without corresponding or matching adjustments in the healthcare system. As a result, both physicians and healthcare executives are frustrated. The present adversarial tone between healthcare executives and physicians adversely impacts healthcare outcomes.

However, the two share common core values: altruism, service, and love of a challenge. They also have common concerns about the future.

\section{Table 1: Doctor-manager relationship}

\begin{tabular}{|c|c|}
\hline Doctors need managers & Managers need doctors \\
\hline $\begin{array}{l}\text { To resolve complexity of the working environment, } \\
\text { which needs managing }\end{array}$ & - \\
\hline To help them with unrealistic expectations & $\begin{array}{l}\text { To ground them in the human and clinical reality of patient } \\
\text { care }\end{array}$ \\
\hline To mediate with the regulations/policy & To translate policy into clinical reality \\
\hline To set boundaries of care & $\begin{array}{l}\text { To recognise where boundaries are ineffective, unrealistic } \\
\text { or inhumane }\end{array}$ \\
\hline $\begin{array}{l}\text { To have an overview of the needs of the whole service } \\
\text { and not be influenced by parochial needs or those of the } \\
\text { most powerful and influential }\end{array}$ & $\begin{array}{l}\text { To inform them about the clinical realities in order to } \\
\text { decide on apportionment of resources }\end{array}$ \\
\hline $\begin{array}{l}\text { To get the resources that are required to deliver the } \\
\text { service }\end{array}$ & To use resources effectively and efficiently \\
\hline $\begin{array}{l}\text { To help them understand networking and committee } \\
\text { skills }\end{array}$ & $\begin{array}{l}\text { To communicate evidence-based clinical practice based on } \\
\text { sound scientific principles }\end{array}$ \\
\hline
\end{tabular}

\section{Adversaries:}

Most physicians and nurses simply want to do their work free of hassle, free of pressures of non-availability of resources be the manpower, material, or money,providing high-quality, patient-sensitive care.They see themselves as doing what society wants, what the immediate patient wants and therefore expect society to make it easy, rather than difficult-toimpossible. Unfortunately, most experience the opposite: hindrances and hassles due to diverse expectations and restrictions placed by organizations, managerial personnel, regulatory agencies, and patients. Not surprisingly,clinicians tend to direct their anger and frustration on immediately available,easily identifiable individuals, such as their own managers, rather than some unknown regulator, or economic pressures.

Healthcare executives are responsible for creating conditions that enable and promote quality care while overseeing limited resources. Ultimately, their administrative decisions impact medical care delivery. However, the complexity of modern medicine presents serious challenges to anyone in hospital management who seeks to create an environment free from error, conflict, dissatisfaction, and constant turnover.

Some see the conflict between providers (the term used in the article for Healthcare service providers) and managers as inevitable, mentioning the relationship of fixed supply of funds, but uncontrolled and apparently limitless demand for services.

\section{Change in Function without Change in System:}

In the past, hospital was filled with patients convalescing widespread diseases, accidents, infections, and childbirth. Almost all modern specialties did not exist. Medicine was incapable of caring forpatients with renal failure or premature babies, and therefore such patients were not hospitalized. Older people with heart failure died at home in bed. Government lacked resources and manpower. Private hospitals for specialised patient care was not in place. Healthcare service was taken care by individual doctors practising in their homes with a note prescribing patients with liquids and pills.

Most patients in modern hospitals are gravely, not mildly, ill, requiring complex technologies and highly trained, specialized teams. Over 80 percent of all the medical care available in your hospital did not exist even in the late $90 \mathrm{~s}$. High-acuity patients are extremely resource intensive in terms of equipment, supplies, expertise, personnel, and liability. The hospital now is typically staffed with full-time physicians and hospital-employed nurses. Physicians delegate in-patient care to the full-time staff. Interestingly, 55 percent of all the people who work in a hospital never see or physically touch a patient. The hospital executives are responsible for an annual budget for managing the resources and doctors are provided the resources from within the budget to achieve the targets fixed by the budget.

The entire healthcare paradigm has been radically altered. In view of the alterations, have the relationships between managers and doctors adapted correspondingly to the changes in their roles and responsibilities? They have not, and the absence of this adjustment is, in large measure, the genesis of the so-called gap.

\section{Doctors and Healthcare Executives Are Both Frustrated:}

Both providers and managers, in many ways, feel squeezed 
and frustrated. The physician's role as captain of the team has diminished, and providers, in general, are confused by a system that wants them to do social good works but then puts stumbling blocks in their way.

Managers feel themselves frustrated as well. They do not understand the doctors' failure to recognize, understand, and accept resource constraints. Just as managers are frustrated by their internal environment, so too are they frustrated by the obligations and restrictions placed by the outside world, particularly governmental agencies. They are required to offer services without adequate resources and follow confusing, often contradictory, rules. Managers, like doctors, feel they are in a no-win position.

In addition to the dynamic tensions and adversarial interactions that might naturally occur between management and medicine, each has personal and professional frustration that they must vent. Both tend to focus on the nearest convenient target-those egotistical white coats (symbolically referred to Doctors) or those bean-countingblue suits (referred to Managers).

\section{How They Communicate:}

Providers of healthcare services are trained rigorously in the knowledge base, judgment, and technical skills necessary to be providers. In the past, physicians did not receive training in communication or in cross-cultural relationships that could improve communication capabilities between medical people and management people. The only process that the providers see is their interaction with the patient, rather than a broader process of healthcare. If providers could master process skills, such as communication, team building, and conflict resolution, they could enlist, rather than fight with, their own managers. Successful communication could improve care processes, change the work environment, and possibly regain the doctors' (lost) leadership role in patient care. Unfortunately, each side tends to see a "we-they", adversarial relationship, and they communicate on that basis.

Most agree that a fundamental disparity exists in the minds of many clinicians about how healthcare managers view the world of medicine and its practitioners. Physicians intimately know and relate to the passages doctors endure on their way to becoming licensed practitioners. They intuitively understand, respect, and trust other physicians, even those in management positions, because of sharing a common professional background. Having these career paths in common usually leads to fruitful interactions and philosophical understanding about care delivery issues and problem-resolution methodologies.

In contrast, practicing physicians and hospital executives seldom share the same education, professional career path experiences, or organizational perspective. The two can have great difficulty in reaching an agreement about how care should be delivered and resources apportioned. As a result, communication breaks down, suspicion germinates, and a cultural gulf forms that is extremely difficult to bridge.

\section{Why Adversaries? Comparison of attributes:}

For physicians, educational background and licensure / accreditation requirements are highly structured and provide common passage for all doctors, nurses, and therapists. This creates bonds of cohesion among clinicians. Socialization during postgraduate training, particularly the role models of teachers, emphasizes personal responsibility, individual goal setting, and autonomous decision making. Physicians have little knowledge and less interest in rule-following bureaucracy, organizational structure, accounting, personnel management, or strategic planning.

Those in management have a very wide diversity of educational backgrounds and no set job accreditation or licensure process. Not only is this markedly different from doctors, but during socialization, managers learn to make group decisions and to delegate responsibility. In strategic planning, managers generally try to forecast and anticipate, while physicians are typically in reactive mode, responding to the acutely ill patient.

In theory, the two sides of the gap have different time horizons: short- ormoderate-term for doctors and long-term for healthcare executives. However, most healthcare managers are now judged on the variance from their monthly or annual budget. Because of the incentive structures and the constantly changing mandates, as well as regulations, healthcare executives are forced to focus on immediate concerns and ad hoc crisis management.

Changes in healthcare over the past 50 years have had profound effects on the power relationships within medicine. The power and influence of healthcare executives has increased with corresponding fall in power and prestige of physicians.

Nevertheless, each side sees itself as on the top of the power pyramid, that is, most important in the system. Doctors reason that, as the patient comes first and the physician or nurse are the only people legally allowed to touch the patient, they must be on the top of the power hierarchy. In any situation involving strategic decisions and financial issues, the healthcare executive is responsible. Since the ultimate decision maker is the hospital CEO, he or she must be at the top of the power hierarchy.

A real important, but subliminal, cognitive difference is the value of business. While working for a hospital, academic physicians are socialized to disregard or at best ignore money, as everything should be done for the patient without regard to expense. Physicians in private practice, however, have a 
similar problem to hospital executives: trying to balance escalating expenses with fixed revenues, while they have control over neither. The physicians' philosophy places patient survival first, while for those in healthcare administration, the institution must survive by having the budget balance.

Despite the host of divergences between doctors and healthcare executives, we find that common core values - altruism, service, and the challenge - motivate both.

\section{Table 2: Comparison of Attributes}

\begin{tabular}{|l|l|l|l|l|}
\hline \begin{tabular}{l} 
S.No \\
\hline
\end{tabular} & Attribute & $\begin{array}{l}\text { Providers of Health Care } \\
\text { (Medicine) }\end{array}$ & \multirow{2}{*}{$\begin{array}{l}\text { Organisational Decision } \\
\text { Makers (Management) }\end{array}$} \\
\hline 1 & Responsibility & Personally held & \\
\hline $\begin{array}{l}\text { Organisational; often } \\
\text { delegated }\end{array}$
\end{tabular}

Relations between physicians and healthcareexecutives directly impact outcomes:

Today's medical centre is a complex, matrix-structured organization. The results of modern medicine are summation effects of the activities of large numbers of people in multiple teams. The " 'one-ill, one-pill, one-bill doctor' is a thing of the past," wrote Wittkower and Stauble over 35 years ago. When a general patient goes for a check-up, his/her care involves a general physician, several office staffs, computer programs, central supply, patient transport, separate laboratories, super specialities, super specialists, supporting non-medical staffs. These diverse elements encompass function and expertise of both white coats and blue suits. To the extent that medicine and management relate well, the patient gets what he or she needs. If physicians and hospital executives function independently (minimal interaction), the care will be fragmented, less effective, and inefficient. If the providers and managers think and behave as adversaries, it is a wonder that anyone gets care at all. Forces external to the medical centre further complicate relations between doctors and healthcare executives. These elements include accreditation and licensure entities, forprofit medical companies such as the pharmaceuticals, and of course, governments. The rules, regulations, and laws must be interpreted and to variable extents implemented by both physicians and healthcare executives.

\section{What Is the Gap?}

The gap represents a gulf, both substantive and perceived, between managers and care providers. The gap includes differences in thinking and approach, priorities and incentives, and responsibilities as well as roles. Most of the substantive distinctions are due to divergent educational backgrounds, temperament and self-selection, radically different professional socialization, alternate world views, and specific expertise.

The two sides also tend to have orthodox and negative perceptions of each other. The manager sees a doctor who has no understanding of or interest in resource constraints or proper organizational behaviour. The doctor sees a heartless bean counter who cares nothing for patients, despite the manager spending all his time and efforts before regulatory authority, resource providers and government aggressively seeking support for the doctors' medical programs.

However, Physicians and Managers (representing healthcare executives) share common core values. We suspect this similarity may surprise both sides of the gap. Such basic, gutlevel commonality can provide the structural supports to bridge the gap.

\section{Bridging the gap:}

The first step would be to understand physician-hospital executive relationship. The differences between physicians and healthcare executives can be used to great advantage. We need to embrace this diversity rather than eliminate it. Combining the diverse talents of physicians and healthcare executives could dissolve many of the problems healthcare faces every day.

\section{Collaboration Is the Beginning:}

It is believed that collaboration between medical schools and management schools can begin to dissolve healthcare woes. Management knowledge and expertise, and business experience and tools have much to offer healthcare. Many emerging healthcare facilitators have demonstrated the potential utility of proven management principles in the healthcare arena. In collaboration, a medical school and a management school can begin to achieve high-quality, reduced-error, resource-sensitive healthcare. However, we also have noted with concern that most universities lack any 
bridge — physical, philosophical, cognitive — across what we call the chasm separating medical schools from their university-affiliated management schools. We believe that an analogous and equally unhealthy separation exists within most medical centres between the providers and the managers. We call this schism the Gap.

\section{Some Strategies for improvement:}

\section{Relationships}

$\diamond$ Respect for differences between managers and doctors

$\diamond$ Develop goals and strategies that are aligned with the clinicians involved

$\diamond$ Education - managers to learn about medicine and doctors about management techniques and how to navigate bureaucracies

$\diamond$ Staff stability to enable working relationships to develop

\section{Reflective practice}

$\diamond$ The capacity to stand back when there are conflicts in order to analyse the problem

$\diamond$ Consult a disinterested party

\section{Educational}

$\diamond$ For both doctors and managers to be educated on the impact of psychological processes at the organisational level

$\diamond$ Develop an academic basis for management and medical management/clinical leadership

$\diamond$ Foster early interdisciplinary education. Managers attending ward rounds and doctors attending management programmes

$\diamond$ Better management research to redesign care processes based on best practice

\section{What we can conclude?}

In computer terms, both physicians and healthcare executives should delete their files containing stereotypical images of each other. They need to learn who the other really is and accept the fact that they have similar core values: altruism, service, and love of a challenge. As suggested before, this can provide the foundation for a bridge across the Gap.

Physicians and managers need to learn about and learn from each other. If they do so, their differences can become strengths. Physicians need to educate executives about research and rigorous science so that managerial decisions can be based on proof rather than just logic. Healthcare executives need to educate doctors about proper management, from financial planning to proven error-reduction techniques and application of queuing theory, namely, in the ER. There are dozens of powerful and applicable business-proven management tools and approaches that can be adapted to healthcare. Together, physicians and healthcare executives can accomplish most of their goals-in-common. If they continue the present adversarial relationship, nothing will improve. What Benjamin Franklin said about revolutionary politics is equally true for the revolution needed in healthcare: "We must hang together, gentlemen. . . else we shall most assuredly hang separately".

\section{REFERENCES}

1. Pathman, D. E., T. R. Konrad, E. S. Williams, W. E. Scheckler, M. Linzer, and J. Douglas. 2002. "Physician Job Satisfaction, Dissatisfaction, and Turnover." Journal of Family Practice 51: 593.

2. Waldman, J. D., J. N. Hood, H. L. Smith, and S. Arora. 2004. "Changing the Approach to Workforce Movements: Application of Net Retention Rate in Healthcare." Journal of Applied Business and Economics 24 (2): 38-60.

3. Waldman, J. D., J. N. Hood, and H. L. Smith. 2006. "Hospital CEOs and Physicians-Reaching Common Ground." Journal of Healthcare Management 51 (3): 171-187.

4. Kissick, W. L. 1995. "Medicine and Management-Bridging the CulturalGaps." Physician Executive 21: 36

5. Wittkower, E. D., and W. J. Stauble. 1972. "Psychiatry and the Role of theGeneral Practitioner." Psychiatry in Medicine 3: 287-301.

6. Arndt, M., and B. Bigelow. 2000. "The Transfer of Business Practices intoHospitals: History and Implications. "Advances in Health Care Management 1:339-368.

7. Waldman, J. D., and R. A. Spector. 2003. "Malpractice Claims Analysis Yields Widely Applicable Principles." Pediatric Cardiology 24 (2): 109-117.

8. Waldman, J. D., S. A. Yourstone, and H. L. Smith. 2005. "Learning -TheMeans to Improve Medical Outcomes." Proceedings of the Decision Sciences Institute2005: 12041-12046.

9. Franklin, B. n.d. Quote World. Available at: http://www. quote world.org/quotes/4954. Accessed March 8, 2015. 